\title{
FLORA DA SERRA DO CIPÓ, MINAS GERAIS: HYPOXIDACEAE ${ }^{1}$
}

\author{
MAURA ALBERGARIA PENA, MAURÍCIO TAKASHI COUTINHO WATANABE \\ \& PAULO TAKEO SANO
}

\begin{abstract}
Departamento de Botânica, Instituto de Biociências, Universidade de São Paulo, Trav. 14, 321, Cidade Universitária, 05508-090 - São Paulo, SP, Brasil.
\end{abstract}

\begin{abstract}
Flora of Serra do Cipó, Minas Gerais: Hypoxidaceae). This study of Hypoxidaceae is part of the project "Flora of Serra do Cipó, Minas Gerais, Brazil”. The family is represented in the area by the species Hypoxis decumbens L. Description, illustration, comments on habitat, geographic distribution, phenology and morphological variability are provided.
\end{abstract}

\begin{abstract}
Resumo - (Flora da Serra do Cipó, Minas Gerais: Hypoxidaceae). Este estudo de Hypoxidaceae é parte do projeto "Flora da Serra do Cipó, Minas Gerais, Brasil”. A família está representada na área somente pela espécie Hypoxis decumbens L. São apresentados descrição, ilustração, comentários sobre hábitat, distribuição geográfica, fenologia e variabilidade morfológica.
\end{abstract}

Key words: Hypoxidaceae, Serra do Cipó, floristics, campo rupestre vegetation.

\section{Hypoxidaceae}

Ervas terrestres, perenes. Rizomas tuberosos ou cormos. Folhas em roseta, sésseis ou raramente constritas junto à base formando pseudopecíolo, lineares a lanceoladas, pilosas a glabras. Inflorescências terminais, racemosas a umbeliformes, às vezes reduzidas a flores solitárias, usualmente bracteadas; escapos geralmente pilosos. Flores freqüentemente pediceladas, monoclinas, raramente diclinas, trímeras, actinomorfas; tépalas 6 , amarelas a laranja, alvas, raramente vermelhas, persistentes, em dois verticilos, livres ou basalmente fundidas entre si. Estames 6, raramente 3 ou 4, freqüentemente unisseriados, eretos; filetes curtos, inseridos na base ou no ápice do perianto; anteras rimosas, alongadas, basifixas ou dorsifixas, biloculares, introrsas, podendo apresentar apêndices apicais. Ovário ínfero, tricarpelar, trilocular, raramente unilocular, placentação axial ou raramente parietal, pluriovulada, óvulos anátropos; nectários ausentes; estilete curto, colunar, fistuloso, estigma capitado a 3-ramificado, com ramos unidos ou livres. Fruto cápsula, deiscência circuncisa ou loculicida, podendo ser indeiscente ou irregularmente deiscente em menor freqüência; sementes globosas a elipsóides, lisas, rostradas, às vezes verrucosas ou papilosas, apresentando grossa camada de fitomelanina, freqüentemente preta, raramente cinzenta.
Família composta por nove gêneros e ca. 100 espécies, ocorrendo principalmente nas regiões tropicais e subtropicais da África, Ásia, Austrália e Américas (Nordal 1998, Dutilh 2005), com maior concentração no hemisfério sul (Nordal 1998). Algumas espécies da família são utilizadas como plantas medicinais na África (Dutilh 2005). No Brasil, são encontrados apenas dois gêneros: Curculigo $e$ Hypoxis (Dutilh 2005). Estudos filogenéticos (Chase et al. 1995, Rudall 2003) têm demonstrado uma forte relação entre Hypoxidaceae e Orchidaceae, entretanto trabalhos mais recentes (Chase et al. 2006) posicionam Orchidaceae como possível grupo-irmão de todas as Asparagales, incluindo Hypoxidaceae.

Bibliografia básica - Seubert (1847), Baker (1880), Brackett (1923a, 1923b).

\section{Hypoxis L.}

Rizomas tuberosos ou cormos, globosos, alongados ou elipsóides. Folhas sésseis, eretas ou ascendentes, lineares a lanceoladas, geralmente pilosas, às vezes desintegrando-se em fibras persistentes na base. Inflorescência em racemos ou cimas, paucifloras; escapo geralmente filiforme, ascendente, piloso, flexuoso; brácteas, quando presentes, subula-

1 Trabalho realizado segundo o planejamento apresentado por Giulietti et al. (1987). 


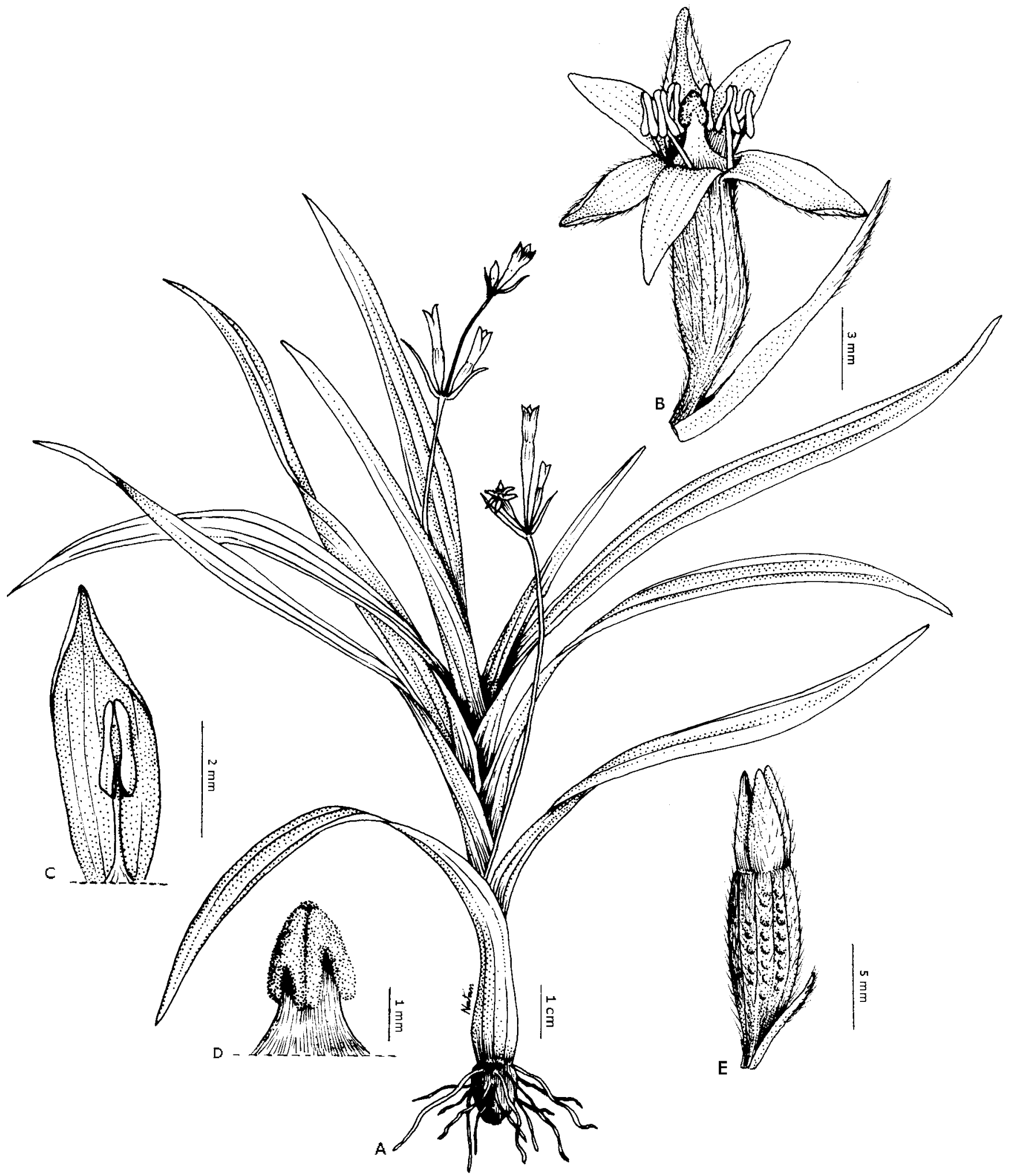

Fig. 1. A-E: Hypoxis decumbens L. A. hábito; B. flor e bráctea floral; C. estame e tépala.; D. estigma ramificado; E. fruto. 
das a estreitamente lineares. Flores com pedicelos delgados a sésseis; tépalas 6, amarelas ou alvas na face adaxial, livres entre si. Estames 6, bisseriados; filetes inseridos na base das tépalas; anteras basifixas, pouco sagitadas, deiscência longitudinal. Ovário cilíndrico, trilocular, não rostrado, piloso. Cápsula circuncisa ou algumas vezes loculicida, subglobosa a subcilíndrica, geralmente trilobada, parede delgada, não rostrada; sementes rostradas, negras, camada de fitomelanina enrugada.

Trata-se do maior gênero da família, compreendendo ca. 50 espécies distribuídas desde o sul do Canadá até a Argentina, África, Austrália, Ásia tropical e subtropical (Huft 1994), em diferentes habitats, desde substratos rochosos com pouca disponibilidade hídrica até regiões encharcadas e brejosas (Nordal 1998). O gênero possui problemas de delimitação das espécies, devido à grande ocorrência de hibridação e apomixia (Sklenar 2005).

1.1. Hypoxis decumbens L., Pl. Jamaic. Pug. 11; Syst. nat. ed. 10. 986; Sp. Pl.: 473. 1753.

Fig. 1 A-E

Nomes populares: falsa-tiririca, mariçô-bravo, maririçósilvestre, tiririca, tiririca-brava e tiririca-de-flor-amarela (Lorenzi 1991).

Erva, ca. $30 \mathrm{~cm}$ alt., rizoma tuberoso, fibroso, cilíndrico a elipsóide, 0,7-1,8 cm espessura. Folhas ascendentes, membranáceas, 6-41 x 0,3-1,1 cm, lineares a lanceoladas, largamente acuminadas, esparsamente pilosas a glabrescentes, margem inteira. Inflorescência com (1)-2-4 flores, racemosa, axilar, hirsuto-pilosas, tricomas amarelos; brácteas $0,4-1,7 \mathrm{~cm}$, filiformes a lanceoladas, acuminadas. Flores 0,7-1,9 cm compr., pedicelo delgado $2-8 \mathrm{~mm}$ compr., piloso; tépalas 4-7 x 1-2 mm, as externas amarelas na face adaxial com tricomas alvos concentrados no ápice, elíptico-lanceoladas, agudas, pilosas externamente, fortemente enervadas; as internas glabras ou pouco pilosas, face adaxial amarela, abaxial esverdeada. Estames livres; anteras bitecas, sagitadas. Ovário ca. 2 mm compr., hipanto esverdeado, piloso; estilete 2-3 mm. Cápsula com deiscência circuncisa, ca. $4 \mathrm{~mm}$ compr., cilíndrica a levemente elipsóide, geralmente pilosa; sementes ca. $1 \mathrm{~mm}$ compr., subglobosas, ápice mucronado, apresentando tuberosidade obtusa a afilada.

Material examinado: Minas Gerais, Santana do Riacho, Serra do Cipó, rodovia Belo Horizonte - Conceição do Mato Dentro, km 142, na bifurcação da estrada, 31.X.1985, N.S. Chukr et al. CFSC 9361, fl., fr. (SPF); km 130, margem da estrada, 12.XI.2007, M.A. Pena et al. 728, fl., fr. (SPF); Km 118, atrás da estátua do Juquinha, 13.XI.2007, M.A. Pena \& C. A. Mittelstaedt 729, fl., fr. (SPF).

Material adicional examinado: Bahia, Abaíra, Tijuquinho, $13^{\circ} 16^{\prime} \mathrm{N}-4^{\circ} 54^{\prime} \mathrm{W}$, alt. 1700-1800m, 17.II.1992, R.M. Harley et al. H 52104, fl. (CEPEC, HUEFS, K, SPF); Morro do Chapéu, Ventura, beira do rio um pouco acima do povoado, 4.III.1997, $R$. Harley et al. PCD 6000, fl. (ALCB, SPF); Minas Gerais, Jequitinhonha, ca. $47 \mathrm{~km}$ ao sul de Pedra Azul, na estrada para Jequiti- nhonha, $16^{\circ} 22^{\prime} \mathrm{S}-4^{\circ} 03^{\prime}, 1100 \mathrm{~m}$ alt., 20.X.1988, R. M. Harley et al. 25276, fl., fr. (K, SPF).

A espécie ocorre nas Antilhas, México Tropical e América do Sul (Brackket 1923a), geralmente em campos abertos, pastos e locais úmidos. É uma erva infestante de jardins e gramados de difícil remoção em decorrência do rizoma subterrâneo (Kissman 1997).

Na Serra do Cipó foram encontrados espécimes em áreas antropizadas como pastos e beiras de estradas. Coletadas com flor entre os meses de outubro e maio

\section{Agradecimentos}

Os autores agradecem a Natanael Santos pela ilustração. $\mathrm{O}$ primeiro e segundo autores agradecem ao CNPq e à CAPES, respectivamente, pelas bolsas de Mestrado concedidas. Paulo Sano agradece ao CNPq pela Bolsa de Produtividade em Pesquisa.

\section{Referências}

BAKER, J.G. 1880. A Synopsis of Hypoxidaceae. Journ. Linn. Soc. 17 (c.1): 93: 126.

BRACKETT, A. 1923a. Revision of the American species of Hypoxis. Rhodora 25 (296): 120-147.

BRACKETT, A. 1923b. Revision of the American species of Hypoxis. Rhodora 25 (297): 151-163.

CHASE, M.W., DURVAL, M.R., HILLS, H.G., CONRAN, J.G., COX, A.V., EGUIARTE, L.E., HARTWELL, J., FAY, M.F., CADDICK, L.R., CAMERON, K.M. \& HOOT, S. 1995. Molecular phylogenetics of Lilianae. In P.J. Rudall, P.J. Crib, D.F. Cutler \& C.J. Humphries (eds.) Monocotyledons: systematics and evolution. Royal Botanic Garden. Kew. p. 109-137.

CHASE, M.W., FAY, M.F., DEVEY, D.S., MAURIN, O., RØNSTED, N., DAVIES, J., PILLON, Y., PETERSEN, G., SEBERG, O., TAMURA, M.N., ASMUSSEN, C.B., HILU, K., BORSCH, T., DAVIS, J.I., STEVENSON, D.W., PIRES, J.C., GIVNISH, T.J., SYTSMA, K.J., McPHERSON, M.M., GRAHAM, S.W. \& RAI, H.S. 2006. Multigene analyses of monocot relationships: a summary. In J.T. Columbus, E.A. Friar, J.M. Porter, L.M. Prince \& M.G. Simpson (eds.) Monocots: Comparative Biology and Evolution (excluding Poales). Rancho Santa Ana Botanic Garden. Claremont, p. 63-75.

DUTILH, J.H. A. 2005. Hypoxidaceae. In M.G.L. Wanderley, G.J. Shepherd, T.S. Melhem, A.M. Giulietti \& M. Kirizawa (eds.) Flora fanerogâmica do Estado de São Paulo. RiMa, FAPESP. São Paulo, vol. 4, p. 258.

GIULIETTI, A.M., MENEZES, N.L., PIRANI, J.R., MEGURO, M. \& WANDERLEY, M.G.L. 1987. Flora da Serra do Cipó, Minas Gerais: Caracterização e lista de espécies. Bol. Bot. Univ. São Paulo 9: 1-151.

HUFT, M.J. 1994. Hypoxidaceae. Flora Mesoamericana 6: 51-53.

KISSMANN, K.G. 1997. Plantas infestantes e nocivas, Tomo I. ed. 2. BASF. Hong Kong.

LORENZI, H. 1991. Plantas daninhas do Brasil: terrestres, aquáticas, parasitas, tóxicas e medicinais. ed. 2. Ed. Plantarum. Nova Odessa. 
NORDAL, I. 1998. Hypoxidaceae. In K. Kubitzki (ed.) The families and genera of vascular plants. III. Flowering Plants. Monocotyledons. Lilianae (except Orchidaceae). Springer. Berlin, p. 286-294.

RUDALL, P.J. 2003. Unique floral structures and iterative evolutionary themes in Asparagales: Insights from a morphological cladistic analysis. Bot. Rev. 68: 488-509.
SEUBERT, M. 1847. Hypoxideae. In C.F.P. Martius \& A.W. Eichler (eds.) Flora brasiliensis. Frid. Fleischer. Leipzig, vol. 3, pars 1, p. 49-52.

SKLENAR, P. 2005. Hypoxidaceae. In P. Sklenar, J.L. Luteyn, C.U. Ulloa, P.M. Jorgensen \& M.O. Dillon (eds.) Flora genérica de los Páramos. Guía ilustrada de las plantas vasculares. The New York Botanical Garden. New York, p. 288 - 289. 